\title{
Depletion of Norepinephrine, But Not Serotonin, Reduces Long-term Potentiation in the Dentate Gyrus of Rat Hippocampal Slices ${ }^{1}$
}

\author{
PATRIC K. STANTON AND JOHN M. SARVEY ${ }^{2}$ \\ Department of Pharmacology, Uniformed Services University of the Health Sciences, Bethesda, Maryland 20814
}

\begin{abstract}
Long-term potentiation (LTP) in the hippocampus is a longlasting enhancement of synaptic efficacy produced by a brief, high frequency repetitive stimulation of afferents. LTP has generated a great deal of interest as a candidate mechanism in learning and memory. A recent in vivo study has shown that depletion of norepinephrine (NE) or serotonin (5-hydroxytryptamine, 5-HT) reduced LTP in the dentate gyrus produced by stimulation of the perforant path. However, it was impossible to tell whether this resulted from depletion in the hippocampus, itself, or was secondary to depletion of other brain areas, and no comparison between hippocampal cell fields was done. Therefore, we have examined the effects of depletion of NE or 5-HT on LTP in the dentate and field CA1 of the isolated in vitro hippocampal slice preparation.

We report here that NE depletion markedly reduces the occurrence and amplitude of LTP in the dentate, but not in field CA1. In contrast, depletion of 5-HT does not prevent occurrence of LTP in either area. Furthermore, pharmacologic data indicate that $\beta$-receptor stimulation of adenylate cyclase is probably the mechanism of NE's action in the production of LTP in the dentate. These results suggest that endogenous hippocampal NE is more important to LTP in the dentate than is endogenous $5-\mathrm{HT}$.
\end{abstract}

In the hippocampus, brief, high frequency stimulation of afferents gives rise to a long-lasting increase in the amplitude of the evoked population spike. This enhancement has been termed long-term potentiation (LTP) and has been described for a number of neuronal inputs to the hippocampus (Bliss and Lømo, 1973; Schwartzkroin and Wester, 19/5; Alger and Ieyler, 1976). The amplitude of the postsynaptic population spike is up to 10 times greater than the response prior to repetitive stimulation (Schwartzkroin and Wester, 1975). LTP can last for weeks in the intact animal (Bliss and GardnerMedwin, 1973; Douglas and Goddard, 1975), and for the life of the hippocampal slice (10 hr or longer) (Alger and Teyler, 1976; Andersen et al., 1977). The extremely long duration of hippocampal LTP

Received October 2, 1984; Revised January 3, 1985;

Accepted January 5, 1985

\footnotetext{
' This work was supported by Uniformed Services University of the Health Sciences Grant CO7514. We thank Dr. Diana Malcolm for her advice and assistance with the spectrofluorometric assays for norepinephrine and serotonin, and with the lateral ventricle injection technique. Also, we thank $\mathrm{Dr}$. Terry C. Pellmar, Dr. Andrew M. Williamson, and Helen Scharfman for their advice on earlier manuscript versions. The expert assistance with graphics by Ms. Georgette Yakalis is most gratefully acknowledged.

${ }^{2}$ To whom correspondence should be addressed.
}

and the possible involvement of the hippocampus in memory processes (Milner, 1972; Berger, 1984) have led to suggestions that LTP may be a good model for learning and memory (Swanson et al., 1982).

In addition to other extrinsic and intrinsic pathways terminating in the hippocampus, there are major afferent systems arising from noradrenergic and serotonergic nuclei of the brainstem that project widely to the hippocampus. Noradrenergic innervation of the hippocampus arises from neurons of the locus ceruleus. Noradrenergic fibers travel in the dorsal noradrenergic bundle, join the median forebrain bundle, and then enter the hippocampus by three pathways: through the ventral amygdaloid bundle-ansa peduncularis, the ipsilateral fasciculus cinguli, and the fornix (Ungerstedt, 1971; Lindvall and Björklund, 1974). The densest projection is to the layer interior to the granule cell layer of the dentate gyrus, followed by stratum radiatum of $\mathrm{CA} 3$ and stratum lacunosum of $\mathrm{CA} 1$ and $\mathrm{CA} 2$ (Crutcher and Davis, 1980; Loy et al., 1980).

The serotonergic innervation of the hippocampus arises almost exclusively from neurons of the median raphe nucleus, ascends in the median forebrain bundle, and passes via the fornix and cingulum to the hippocampus. Again, the densest innervation is found in the interior borders of the dentate granule cell layer, although other hippocampal areas are also well innervated (Conrad et al., 1974; Azmitia and Segal, 1978). Stimulation of each of these pathways can modulate both the spontaneous activity of single units and the amplitude of evoked potentials from other inpuls (Seyal and Bloom, 1974; Bliss and Wendlandt, 1977; Winson, 1980). In addition, there is evidence that these ascending pathways are involved in the reinforcement of conditioned behavior (Stevens et al., 1969; Crow and Wendlandt, 1976; Mason and Iversen, 1977). Furthermore, depletion of norepinephrine (NE) has been shown to alter perforant path transmission through the dentate gyrus (Dahl et al., 1983).

$A$ recent in vivo study has shown that LTP in the dentate is reduced by prior depletion of NE by 6-hydroxydopamine (6-OHDA), or of serotonin (5-hydroxytryptamine, 5-HT) by 5,7-dihydroxytryptamine (5,7-DHT) or p-chlorophenylalanine (PCPA) (Bliss et al., 1983). However, it was impossible to tell in vivo whether this resulted from depletion in the hippocampus itself, or depletion of other brain areas. Since stimulation of a variety of other brain areas has been shown to influence hippocampal neuronal excitability (Segal and Bloom, 1974; Winson, 1980; Swanson et al., 1982), it is possible that depletion of a noradrenergic or serotonergic input to one of these areas might secondarily modulate LTP in the hippocampus. In addition, generalized stimulation of the angular bundle in vivo may antidromically stimulate brain areas supplying axons to this input (e.g., the median raphe; Conrad et al., 1974; Azmitia and Segal, 1978), which may in turn project to the hippocampus either directly or through other brain areas (e.g., the locus ceruleus; Conrad et al., 1974). Therefore, we elected to examine the effects of depletion of NE or 5-HT on LTP in the in vitro hippocampal slice preparation. In this way, we could isolate the hippocampus from from tonic extrahippocampal inputs and apply compounds in the bath at known 
concentrations. We employed depletion methods identical to those in the in vivo study (Bliss et al., 1983), to facilitate data comparison.

We report here that NE depletion specifically and markedly reduces LTP in the dentate, as measured by frequency of occurrence and population spike amplitude, but has no effect on LTP in field CA1. In contrast, depletion of 5-HT does not reduce frequency of occurrence of LTP, and only slightly reduces the degree of potentiation of population spike amplitude, in the dentate, and has no effect on LTP in field CA1. Furthermore, pharmacologic studies indicate that $\beta$-receptor stimulation of adenylate cyclase is important for LTP in the dentate. These results suggest that endogenous hippocampal NE is more important to LTP in the dentate than is endogenous 5 HT. A part of this work has been published previously in abstract form (Stanton and Sarvey, 1984a).

\section{Materials and Methods}

Animals. Male Sprague-Dawley rats (150 to $250 \mathrm{gm}$ ) were obtained from Hilltop Laboratory Animals (Scottsdale, PA)

Materials. The hydrochlorides of 6-hydroxydopamine, 5,7-dihydroxytryptamine, para-chlorophenylalanine, 5-hydroxytryptamine, and norepinephrine, and O-pthaldehyde, and iodine were obtained from Sigma Chemical Co. (St. Louis, MO). n-Heptane and butanol were obtained from Fischer Scientific (Pittsburgh, PA). Forskolin was kindly donated by Dr. John W. Daly, National Institute of Arthritis, Diabetes, Digestive, and Kidney Diseases, National Institutes of Health (Bcthcsda, MD). Desmcthylimipramine hydrochloride was the generous gift of Dr. T. P. Pruss, Revlon Health Care Group (Tuckahoe, NY).

Electrophysiology. Transverse hippocampal slices ( $400 \mu \mathrm{m}$ thick) were prepared with a Mcllwain tissue chopper (Brinkmann Instruments Co., Westbury, NY). Slices were placed on a nylon mesh at the interface between buffer and a humidified atmosphere of $95 \% \mathrm{O}_{2} / 5 \% \mathrm{CO}_{2}$ and were continuously perfused with physiologic solution at $35^{\circ} \mathrm{C}$ and $\mathrm{pH} 7.2$. The modified Krebs-Ringer buffer had the following ionic composition (in millimolar concentration): $\mathrm{NaCl}, 124 ; \mathrm{KCl}, 5 ; \mathrm{MgSO}_{4}, 1.3 ; \mathrm{KH}_{2} \mathrm{PO}_{4}, 1.25 ; \mathrm{NaHCO}_{3}, 26$; glucose, $10 . \mathrm{CaCl}_{2}$ was titrated to give a free $\left[\mathrm{Ca}^{2+}\right]$ of $2.2 \mathrm{~mm}$, as measured by a $\mathrm{Ca}^{2+}$-sensitive electrode.

Slices were capable of producing stable orthodromic responses for at least $8 \mathrm{hr}$. Stimuli were delivered with bipolar electrodes placed either on the Schaffer collateral axon fibers in stratum radiatum or on the perforant path axons in stratum moleculare. Orthodromic field potentials were recorded with glass microelectrodes ( $2 \mathrm{M} \mathrm{NaCl}, 2$ to 5 megohms) placed in the CA1 pyramidal or dentate jranule cell body layer, respectively.

Drugs were applied extracellularly at known concentrations by switching perfusion reservoirs. The perfusion flow rate was maintained at $3 \mathrm{~m} / \mathrm{min}$ with a peristaltıc pump. All drugs, with the exception of forskolin, were directly soluble in physiołogic buffer at all concentrations employed. Forskolin was first dissolved in dimethylsulfoxide (DMSO) to a concentration of $100 \mathrm{~mm}$ and then was diluted in physiologic buffer. The largest concentration of DMSO in forskolin solutions employed was $0.14 \mathrm{~mm}$, whereas 100 times that concentration of DMSO tested alone had no effect on neuronal excitability. Furthermore, DMSO concentrations as high as $500 \mathrm{~mm}$ have been shown not to affect forskolin-stimulated adenylate cyclase activity (Huang et al., 1982)

Prior to repetitive stimulation, slices were incubated for $60 \mathrm{~min}$, and three repetitions of the base line input-output relation $(1 / O$; stimulus intensity versus population spike amplitude) were determined over a 15-min period. Then slices were repetitively stimulated with 200 pulses at either $20 \mathrm{~Hz}$ for $10 \mathrm{sec}$ via the stratum radiatum in $\mathrm{CA} 1$, or $100 \mathrm{~Hz}$ for $2 \mathrm{sec}$ via the perforant path in the dentate, with an intensity that evoked a population spike of approximately $40 \%$ of the maximal base line response. These stimulus parameters were chosen because they were maximally effective in producing LTP in these areas. $1 / O$ curves were determined at $1,5,15$, and 30 min after repetitive stimulation.

Depletion. Animals to be depleted of NE with 6-OHDA were anesthetized with Chloropent (Fort Dodge Laboratories, Fort Dodge, $\mid \mathrm{A} ; 3 \mathrm{mg} / \mathrm{kg}$, i.p.) and injected bilaterally in the dorsal noradrenergic bundle $(6 \mu \mathrm{g} / \mathrm{side}$ in $2 \mu \mathrm{l}$ of $0.9 \% \mathrm{NaCl}$ containing $0.2 \mathrm{mg} / \mathrm{ml}$ of 1 -ascorbic acid), using the following stereotactic coordinates (measured from zero at the midpoint of the interaural line): $2.4 \mathrm{~mm}$ anterior, $0.8 \mathrm{~mm}$ lateral, and $2.9 \mathrm{~mm}$ dorsal (König and Klippel, 1963). Sham-operated controls were injected with an identical volume of $0.9 \% \mathrm{NaCl}$ plus $/$-ascorbic acid. In some animals, fast green dye $(0.1 \mathrm{mg} /$ $\mathrm{ml})$ was injected into the dorsal noradrenergic bundle or lateral ventricle, to verify penetration of the dye into the desired sile.

Animals were depleted of 5-HT with 5,7-DHT by unilateral freehand injections in the lateral ventricle $(330 \mu \mathrm{g}$ in $0.9 \% \mathrm{NaCl}$ containing $0.2 \mathrm{mg} / \mathrm{ml}$ of l-ascorbic acid), $1.5 \mathrm{~mm}$ lateral to bregma and $3.5 \mathrm{~mm}$ below the skull (Nobel et al., 1967). These animals were pretreated with desmethylimipramine (DM; $20 \mathrm{mg} / \mathrm{kg}$, i.p., in sterile $\mathrm{H}_{2} \mathrm{O}$ ) 40 to $60 \mathrm{~min}$ before $5,7-\mathrm{DHT}$ injection to protect noradrenergic terminals. Sham-operated controls were injected with an identical volume of $0.9 \% \mathrm{NaCl}$ plus /-ascorbic acid. Slices were prepared from these animals 14 to 21 days after injection, when levels of depletion were maximal (Bliss et al., 1983). Animals were depleted of 5-HT with PCPA by two injections, 48 and $24 \mathrm{hr}$ before slice preparation $(400 \mathrm{mg} / \mathrm{kg}$, i.p., in sterile $\mathrm{H}_{2} \mathrm{O}$ )

Biochemical assays. Hippocampi of control and depleted animals were removed, frozen, and stored at $-70^{\circ} \mathrm{C}$ until NE or $5-\mathrm{HT}$ was assayed by specific spectrofluorometric assay (Maickel et al., 1968). In addition, at the beginning of some experiments, one hippocampus was randomly selected for the preparation of slices, while the remaining tissue from this side and the entire contralateral hippocampus were frozen at $-70^{\circ} \mathrm{C}$ tor assay later. These assays permitted resolution down to $2 \mathrm{ng}$ of NE or $5-\mathrm{HT}$, and standard curves were linear over a range of 5 to $100 \mathrm{ng}$. Internal standards were employed to correct for percentage recovery of the extraction procedure, and there was $<1 \%$ cross-reactivity in either assay for the other monoamine or dopamine. Transmitter levels were expressed as nanograms per milligram of protein. (Bradford, 1976).

Data analysis. Extracellular responses were sampled on line by digitizing oscilloscopo (Tektronix, Inc., Beaverton, OR, model 7D20), transferred to a MINC 11/23 computer (Digital Equipment Corp., Marlboro, MA) and stored as the average of eight responses. Spike amplitude was defined as the average of the amplitude from the peak early positivity to the peak negativity, and the amplitude from the peak negativity to the peak late positivity (Alger and Teyler, 1976). Population spike amplitude has been shown to reflect the number and synchrony of neurons tiring in the vicinity of the recording electrode (Andersen et al., 1971), and to correlate with the slope of the excitatory post-synaptic potential (EPSP) as well as with spike latency (Bliss and Gardner-Medwin, 1973). The standard deviation of control spike amplitudes was averaged from pooled control slice standard deviations, and LTP was defined as a spike amplitude increase of greater than 2 SD from the mean of three control base line responses $30 \mathrm{~min}$ after repetitive stimulation. In slices which showed potentiation at this time, potentiation lasted for hours (Stanton and Sarvey, 1984c). An earlier time was not chosen because large spike amplitude increases often occur immediately after repetitive stimulation and last up to $15 \mathrm{~min}$ in the absence of LTP.

All values in the text are expressed as mean \pm SEM. Comparison of the frequency of occurrence of LTP was evaluated by $\chi^{2}$ test, comparing all groups to the control frequency of occurrence of LTP in the appropriate recording area $(75 \%$ for dentate, $N=12 ; 57 \%$ for $C A 1, N=28)$. Comparison of average population spike amplitudes between different groups of slices was evaluated by the two-tailed Student's $t$ test for unpaired observations. The level of significance for all statistical tests was preselected to be $p<$ 0.05 . Linear regression was performed by Newton's method of least squares linear analysis (Goldstein, 1964)

\section{Results}

\section{Transmitter levels in depleted animals}

$N E$. The mean level of hippocampal NE in control animals $(N=$ 8) was $210 \pm 30 \mathrm{pg} / \mathrm{mg}$ of tissue wet weight. In animals injected bilaterally with $6-\mathrm{OHDA}$ in the dorsal noradrenergic bundle and assayed 14 to 21 days later $(N=12)$, the $N E$ concentration was $35.5 \pm 7.8 \mathrm{pg} / \mathrm{mg}$ of tissue. Thus, mean depletion of NE was 83.1 $\pm 5.4 \%$. This value is comparable to depletion produced with these methods in in vivo experiments (Bliss et al., 1983).

Serotonin. The mean level of hippocampal 5-HT in control animals $(N=8)$ was $328 \pm 15 \mathrm{pg} / \mathrm{mg}$ of tissue wet weight. The moan depletion in animals treated with 5,7-DHT plus DMI $(N=5)$ was 69.0 $\pm 6.0 \%$ and in animals treated with PCPA $(N=3), 76.2 \pm 1.4 \%$. These values are also comparable to those produced with these methods in vivo (Bliss et al., 1983).

\section{Depletion of NE specifically reduced LTP in the dentate}

The frequency of occurrence and the percentage of change in the amplitude of the evoked population spike during LTP were compared for normal slices and those depleted of NE or 5-HT. After establishing a stable base line $1 / 0$ rclation for 15 to $30 \mathrm{~min}$, the sliccs were repetitively stimulated via the perforant path for dentate record- 


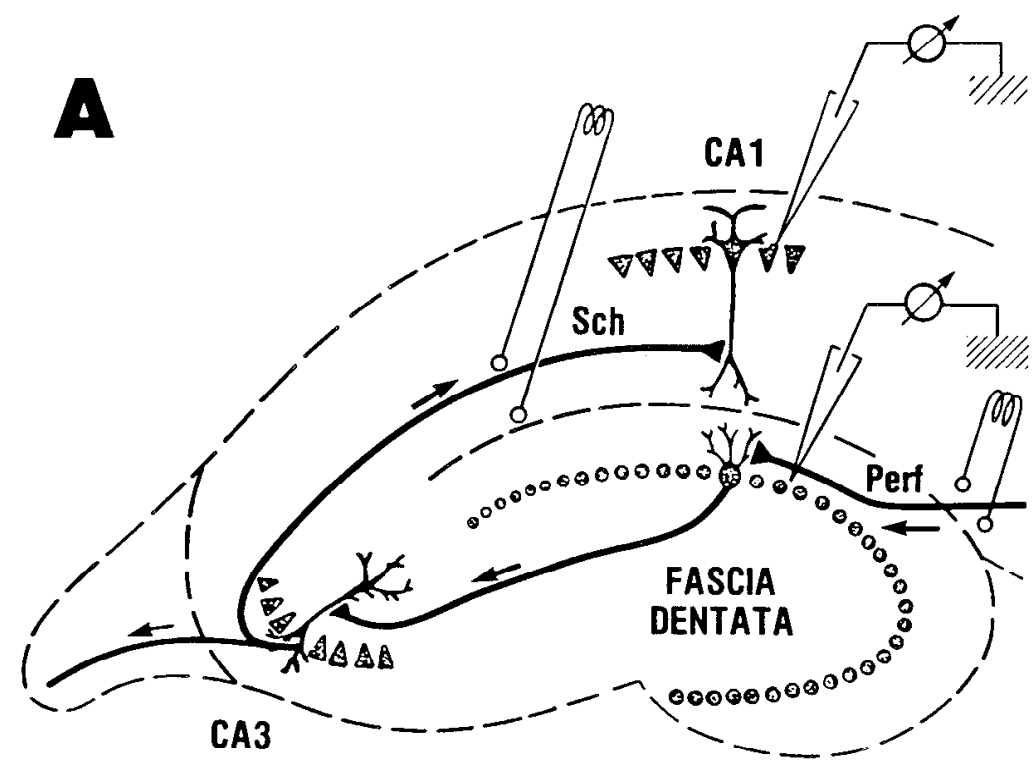

B

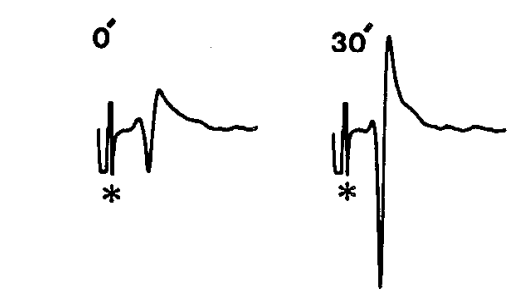

C

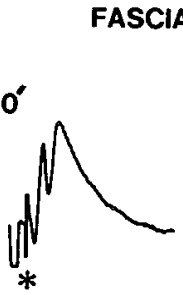

CA1

FCIA DENTATA

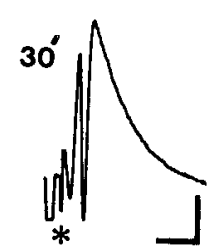

Figure 1. A, The hippocampal slice preparation, showing both recording sites (dentate and CA1) and both stimulus sites (perforant path (Perf) and Schaffer collaterals $(S c h)$ ). Only one set of recording and stimulus sites was employed in a given slice. B, Control LTP in field CAt. The population spike was recorded in CA1 just prior to $\left(0^{\prime}\right)$, and $30 \mathrm{~min}$ after $\left(30^{\prime}\right)$, repetitive stimulation of the Schaffer collaterals $(20 \mathrm{~Hz} / 10 \mathrm{sec})$. The potentiation after $30 \mathrm{~min}$ was $300 \%$ of control spike amplitude. Asterisks denote stimulus artifact. C. Control LTP in the dentate. The population spike was recorded in the dentate, and repetitive stimulation was applied to the perforant path $(100 \mathrm{~Hz} / 2 \mathrm{sec})$. Potentiation here after $30 \mathrm{~min}$ was $225 \%$ of control amplitude. Calibration for $B$ and $\mathrm{C}: 1 \mathrm{mV}, 5 \mathrm{msec}$.

ings, or via the Schaffer collaterals for CA1 recordings. A schematic drawing of the slice with both stimulating and recording paradigms is shown in Figure 1A. Figure 1, B (CA1) and $C$ (derlate), shows examples of population spikes exhibiting LTP 30 min after repetitive stimulation. This potentiation typically lasted for many hours in the slice preparation (Stanton and Sarvey, 1984c).

Dentate. Depletion of NE with 6-ODHA (Fig. $2 A$ ) virtually eliminated both the frequency of occurrence of $\operatorname{LTP}\left(x^{2}, p<0.05\right)$ and the increase in average population spike amplitude (Student's $t$ test, $p$ $<0.05$ ) produced after repetitive stimulation. Slices cut from NEdepleted animals were no different in population spike or dendritic EPSP waveform or amplitude but were markedly impaired in their ability to exhibit LTP in the dentate gyrus.

Experiments to control for depletion of dopamine or other nonspecific effects of the toxin were performed by injecting animals with DMl 40 to 60 min before injection of 6-OHDA, to block uptake of the toxin into noradrenergic nerve terminals. In slices cut from these animals 14 to 21 days later, neither the frequency of occurrence nor the amplitude of LTP differed from those seen in control slices (Fig. 2A).

CA1. In contrast to the dentate gyrus, depletion of NE by 6-OHDA did not impair either the frequency of occurrence or the amplitude of LTP in field CA1, when repetitive stimulation was applied to the Schaffer collaterals (Fig. 2B).

\section{Depletion of 5-HT did not affect LTP in either dentate or CA1}

Dentate. Depletion of 5-HT with either 5,7-DHT or PCP^ was unable to affect the frequency of occurrence of LTP produced in the dentate gyrus by stimulating the perforant path (Fig. $3 A$ ). In the case of 5,7-DHT, there was no significant difference in the average population spike amplitude increase seen during LTP. However, PCPA was able to reduce somewhat the average population spike amplitude increase after repetitive stimulation (Student's $t$ test, $p<$ $0.05)$.

CA1. In field CA1, depletion of 5-HT had no effect on either the frequency of occurrence of LTP or the average population spike amplitude after repetitive stimulation of the Schaffer collaterals (Fig. 3B).
The time course of the recovery of hippocampal NE levels was paralleled by the recovery of LTP in the dentate

Another group of animals was treated with 6-OHDA to deplete hippocampal NE and then was allowed longer periods (21 to 42 days) for hippocampal NE levels to recover. The time course of recovery of hippocampal NE levels was closely paralieled by the recovery of LTP produced in the dentate by repetitive stimulation of the perforant path. Increasing percentage of depletion in the hippocampus was well correlated with a greater reduction in the mean population spike amplitude increase after repetitive stimulation (Fig. $4, r=-0.926$; Student's $t$ test, $p<0.05, r=0$ ). This supports the hypothesis that the reduction in LTP seen with 6-OHDA treatment is due to depletion of hippocampal NE.

\section{The $\beta$-antagonist propranolol and $\beta_{1}$-antagonist metoprolol decrease LTP in the dentate}

Since involvement of NE in production of LTP in the dentate gyrus was strongly supported by our data, the next question became the identification of the noradrenergic receptor subtype mediating the effect. Previous work in our and other laboratories has shown that NE alone, under a variety of application procedures, can produce a long-lasting potentiation of the population spike in the dentate, and that this effect is antagonized by $\beta$-receptor antagonists (Neuman and Harley, 1983; Stanton and Sarvey, 1984b). Thercforc, we began by testing the ability of the $\beta$-antagonist propranolol and the $\beta_{1}$ antagonist metoprolol to affect LTP produced in the dentate by repetitive stimulation of the perforant path.

Slices from nondepleted rats were preincubated for $30 \mathrm{~min}$ with bath-applied propranolol $(20 \mu \mathrm{M})$ or metoprolol $(20 \mu \mathrm{M})$ and then repetitively stimulated via the perforant path. $\beta$-Receptor blockade markedly reduced both the frequency of occurrence $\left(\chi^{2}, p<0.05\right)$ and the increased population spike amplitude (Student's $t$ test, $p<$ 0.05 ) of LTP (Fig. 5). Neither antagonist alone affected the population spike amplitude or waveform. These results further support the conclusion that the action of NE in supporting potentiation of the population spike in the dentate is mediated by $\beta$-receptor activation, and probably $\beta_{1}$-receptors specifically.

In contrast, LTP in field CA1 did not seem to be reduced by 


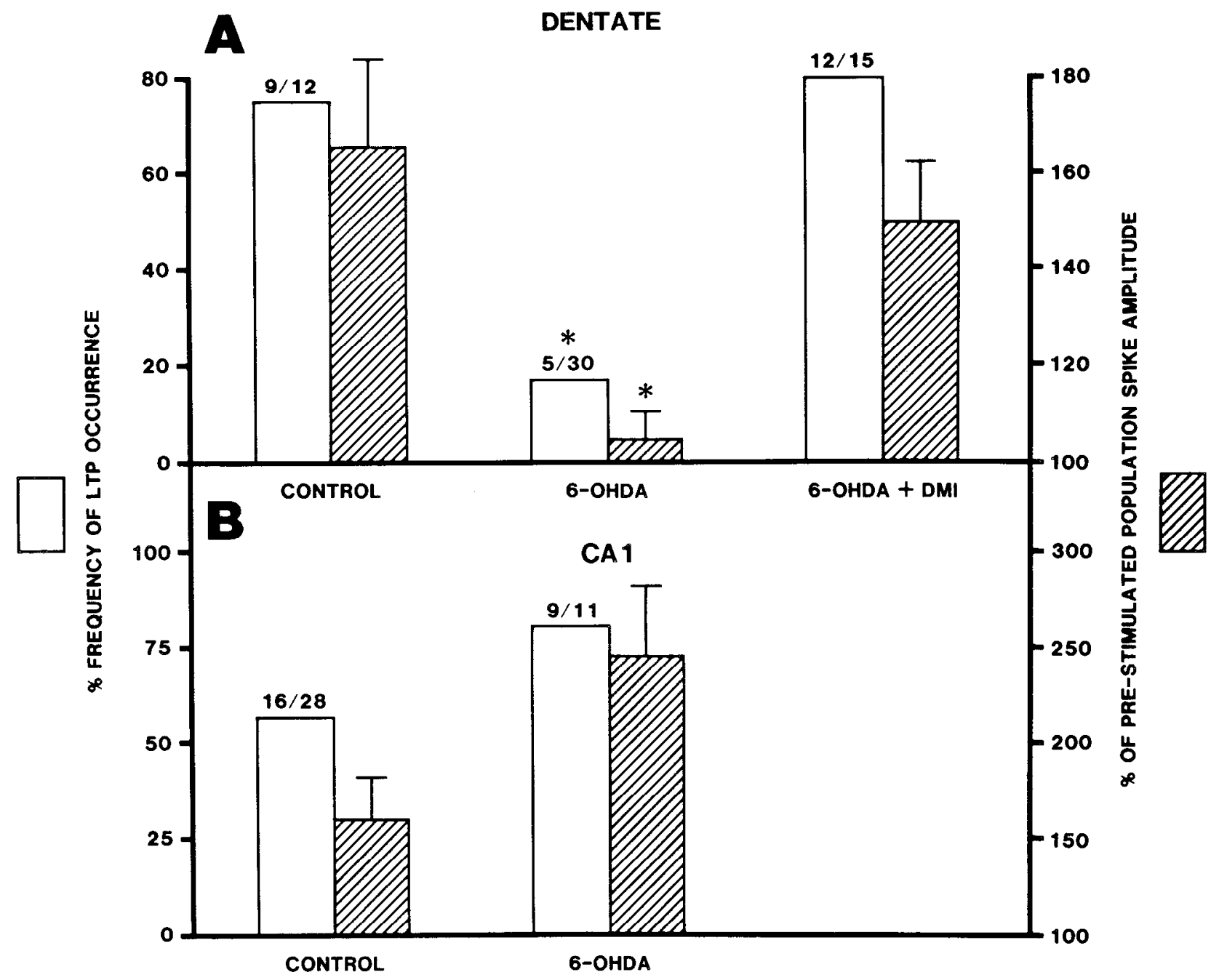

Figure 2. A, Percentage of occurrence of LTP (open bars) and percentage of increase in population spike amplitude (mean \pm SEM, hatched bars), in the dentate $30 \mathrm{~min}$ after repetitive stimulation of the perforant path. Above each open bar is the number of slices showing LTP per total number of slices tested LTP was defined as an increase in population spike amplitude greater than 2 SD over mean control amplitudes 30 min after repetitive stimulation. Depletion of NE by 6-OHDA virtually eliminated both the frequency of occurrence $\left(*, \chi^{2}, p<0.05\right)$ and the increased amplitude $(*$, Student's $t$ test, $p<$ 0.05) of LTP. When animals were pretreated 40 to $60 \mathrm{~min}$ before 6 -OHDA injection with DMl ( $20 \mathrm{mg} / \mathrm{kg}$, i.p.) to prevent uptake of the toxin into noradrenergic terminals, there was no effect on LTP. $B$, In contrast, depletion of NE by 6-OHDA did not impair LTP in field CA1, when repetitive stimulation was applied to the Schaffer collaterals.

preincubation in propranolol $(20 \mu \mathrm{M}$; mean $=202 \%, N=2)$, indicating much less importance for $\beta$-receptors in LTP in this area.

\section{The adenylate cyclase stimulant forskolin restores LTP in the dentate of slices depleted of NE}

Since $\beta$-receptor activation in a wide variety of neuronal systems has been shown to employ $3^{\prime}, 5^{\prime}$-cyclic adenosine monophosphate (CAMP) as an intracellular "second messenger," wo pcrformed experiments to test the importance of adenylate cyclase stimulation by $\beta$-receptors in the action of NE in the dentate. In addition, these experiments demonstrate that NE-depleted slices retain the ability to exhibit LTP in the dentate if adenylate cyclase activation is enhanced.

As previously shown, deplction of NE with 6-OHDA markedly reduced both the frequency of occurrence and the increase in population spike amplitude of LTP in the dentate gyrus (Figs. 2 and 6). However, when 6-OHDA-depleted slices were preincubated for $30 \mathrm{~min}$ with the direct-acting adenylate cyclase stimulant forskolin ( $1 \mu \mathrm{M}$, in $0.14 \mathrm{~mm}$ DMSO) prior to repetitive stimulation, LTP measured 30 min after repetitive stimulation of the perforant path was restored to normal (Fig. 6). This concentration of forskolin alone had no effect on population spike amplitude in the dentate of either depleted $(N=8)$ or control $(N=3)$ slices.

\section{Discussion}

Several conclusions can be drawn from these studies. (1) Depletion of NE with 6-OHDA rcduces both the frequency of occurrence and the population spike amplitude of LTP in the dentate gyrus but not in field CA1. (2) In contrast, depletion of 5-HT with either 5,7$\mathrm{DHT}$ or PCPA does not reduce the occurrence of LTP in either area, although the average increase in population spike amplitude in the dentate is somewhat reduced by PCPA. (3) In 6-OHDA-treated animals that are allowed longer lengths of time for hippocampal NE levels to recover, there is a reversal of the reduction in population spike amplitude which correlates well with the recovery of NE levels. (4) The $\beta$-receptor antagonist propranolol and $\beta_{1}$-receptor antagonist metoprolol are effective blockers of LTP in the dentate but not in field CA1. (5) The adenylate cyclase stimulant forskolin, at a concentration $(1 \mu \mathrm{M})$ which primes the cyclase for enhanced agonist stimulation without directly stimulating cAMP production, reverses the effects of depletion of NE on LTP in the dentate.

In the recent in vivo study examining the effect of depletion of NE or $5-\mathrm{HT}$ on LTP, it was found that depletion of either monoamine yielded significant reductions in LTP produced in the dentate by stimulation of the perforant path (Bliss et al., 1983). In contrast, we have found that depletion of $5-\mathrm{HT}$ produces little or no reduction of 


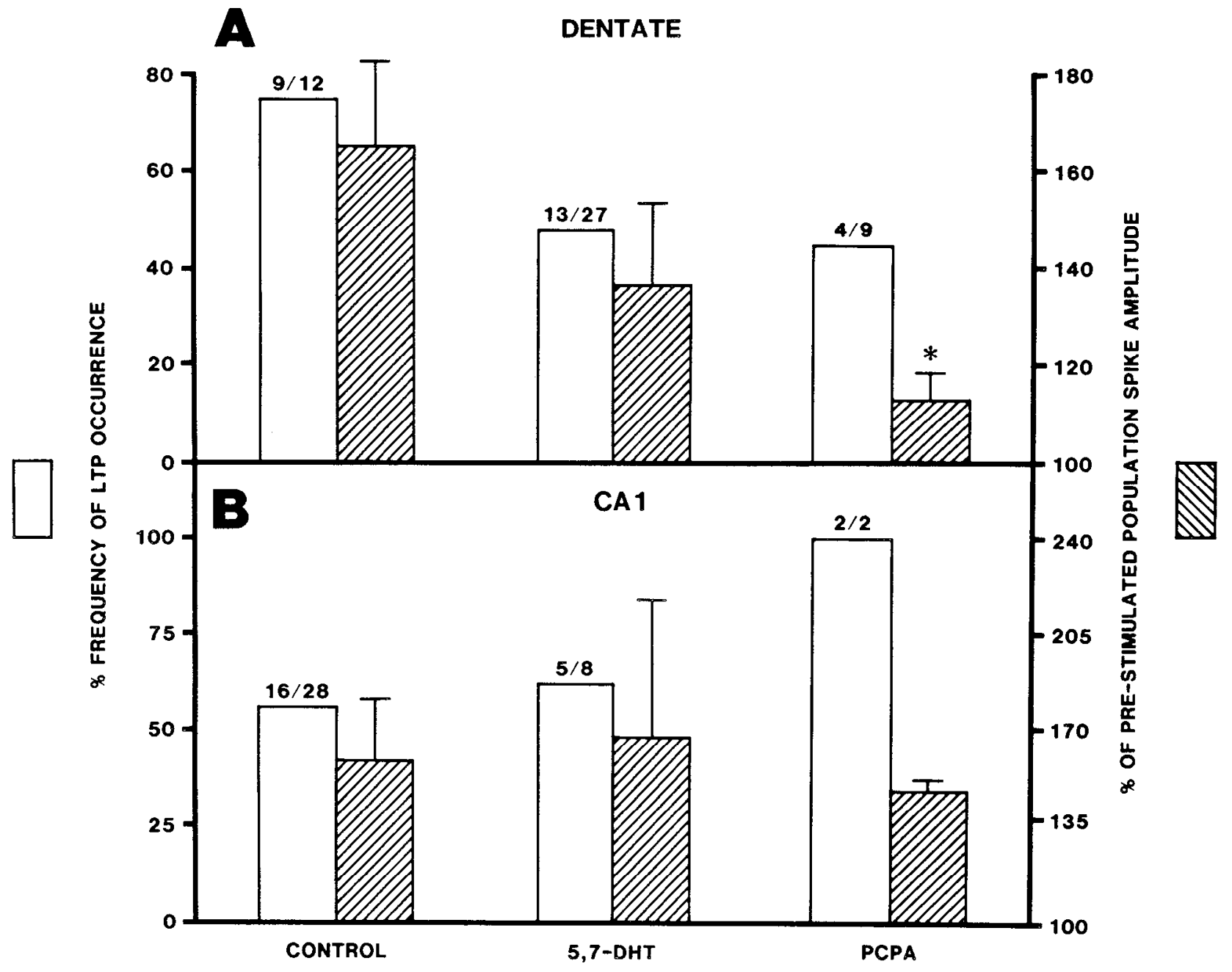

Figure 3. A, Percentage of occurrence of LTP (open bars) and percentage of increase in population spike amplitude (mean \pm SEM, hatched bars) in the dentate $30 \mathrm{~min}$ after repetitive stimulation of the perforant path. Above each open bar is the number of slices showing LTP per total number of slices tested. Depletion of 5-HT with either 5,7-DHT or PCPA produced no decrease in the frequency of occurrence of LTP. However, depletion of 5-HT with PCPA did produce some decrease in the population spike amplitude increase seen in LTP (*, Student's $t$ test, $p<0.05$ ), although there was no significant decrease with 5,7-DHT treatment. $B$, In field CA1, depletion of 5-HT with either 5,7-DHT or PCPA had no effect on either frequency of occurrence or population spike amplitude increase of LTP.

LTP in the dentate of hippocampal slices, but that depletion of NE virtually eliminates LTP in this area. It seems unlikely that we were simply unable to deplete hippocampal $5-\mathrm{HT}$ sufficiently to observe effects on LTP, since the levels of depletion achieved were virtually identical to those produced in the in vivo study of Bliss et al. (1983). The most appealing explanation for this difference is that NE endogenous to the hippocampus is extremely important to the production of LTP in the dentate, but that the importance of $5-H T$ to LTP is at sites elsewhere in the brain. Indeed, there is a significant innervation of the locus ceruleus by neurons of the raphe nuclei (Conrad et al., 1974), and it is possible that deficits in serotonergic transmission in this area might secondarily produce alterations in noradrenergic transmission to the hippocampus in vivo that cannot be operative in vitro. Alternatively, hippocampal 5-HT may presynaptically modulate tonic transmission levels of another hippocampal input, which is altered or no longer effectively modulated by 5 - HT in the explanted slice.

An apparent inconsistency within our findings is the result that PCPA depletion of 5-HT significantly reduced the average increase in population spike amplitude but did not prevent the occurrence of LTP in the dentate, whereas 5,7-DHT depletion of 5-HT had no effect on either. This may be simply due to the slightly larger amount of depletion produced by PCPA. However, it may also be explained by the recent finding that PCPA treatment reduces the affinity of NE for $\beta$-receptors and reduces the amount of CAMP production stimulated by NE in cerebral cortex membrane preparations (Manier et al., 1984).

Although the depletion data presented here suggest an important role for NE localized in the dentate gyrus in the production of LTP, there is no clue to its mechanism of action. There are data indicating that locus ceruleus stimulation can modulate learned task performance (Crow and Wendlandt, 1976; Mason and Iversen, 1977) and can increase the synaptic efficacy of the perforant path input to dentate granule cells (Assaf et al., 1979). In field CA1, extracellular studies have found that NE has both $\beta$-receptor-mediated excitatory and $\alpha$-receptor-mediated inhibitory effects on population spike amplitude (Mueller et al., 1981). Intracellular studies have found NE to hyperpolarize, produce a moderate conductance increase, and decrease excitability, in both CA1 pyramidal neurons (Langmöen et al., 1981) and dentate granule cells (Haas, 1984). Many investigators have suggested that NE preferentially reduces slow synaptic events, while leaving fast depolarizations like EPSPs unaffacted, as a potential way of improving the signal-to-noise ratio of input to the hippocampus (Langmöen et al., 1981; Segal, 1982). Interestingly, recent studies have shown that NE can decrease a $\mathrm{Ca}^{2+}$-dependent $\mathrm{K}^{+}$ current $\left(I_{c}\right)$ in hippocampal pyramidal cells (Madison and Nicoll, 1982; Haas and Konnerth, 1983). This effect remains to be tested in dentate granule cells, but NE may act via such a suppression of 


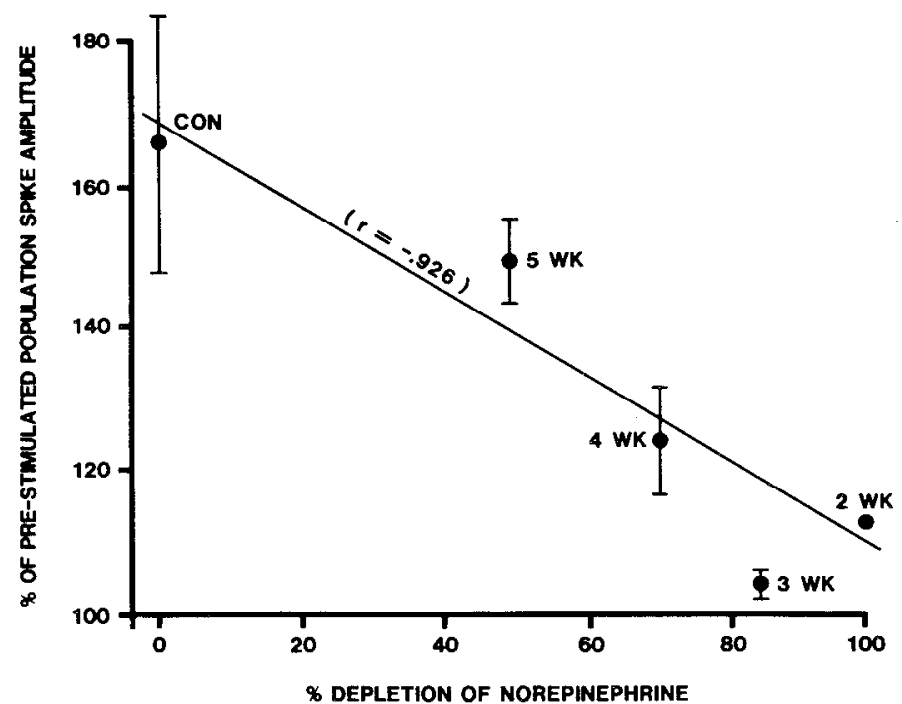

Figure 4. Average percentage of increase in population spike amplitude (mean \pm SEM) recorded in the dentate versus percentage of depletion of hippocampal NE in rats treated with 6-OHDA and allowed varying lengths of time for hippocampal NE levels to recover. The time course of recovery of NE levels was closely paralleled by the return of the ability to produce LTP in the dentate. Increasing percentage of depletion was correlated with smaller increases in average population spike amplitude after repetitive stirmulation ( $r=-0.926$; control, $N=12$ slices; each depleted animal, $N=4$ slices)

$I_{c}$ to increase the repetitive firing of granule cells responding to high frequency stimulation. The specific mechanisms behind NE's importance to LTP in the dentate still remain to be extracted from the variety of noradrenergic receptors and effects reported in the hippocampus.
The most likely site for NE's actions is in the dense terminal layer in the dentate hilus, immediately interior to the dentate granule cell body layer. In this respect, it is interesting to note that a train of stimuli, delivered to either the contra- or ipsilateral hilus just bcforc or during a conditioning train to the perforant path, can prevent the induction of LTP (Douglas et al., 1982). Most directly, recent studies in our and other laboratories have shown that application of NE alone can produce a long-lasting potentiation of the evoked population spike in the dentate (Neuman and Harley, 1983; Stanton and Sarvey, 1984b) but not in field CA1 (Stanton and Sarvey, 1984b).

We have taken the first steps in attempting to elucidate the receptor mechanisms behind NE's action in the dentate. The ability of the $\beta$-receptor antagonists propranolol and metoprolol to reduce LTP in the dentate indicates that $\beta_{1}$-receptor activation is probably important in LTP, and it also strengthens the conclusion that NE endogenous to the hippocampus normally plays a role in the expression of LTP. This conclusion is further supported by the experiments in which the ability to exhibit LTP was restored in slices from NEdepleted animals with a low concentration of forskolin, which was probably acting through enhanced $\beta$-receptor-mediated stimulation of adenylate cyclase. This result assures us that the neuronal mechanisms necessary for the production of LTP are intact in the 6-OHDA-treated animals, but that there simply is not a sufficient concentration of NE for expression of LTP.

Forskolin has been shown to have both a direct stimulating effect on adenylate cyclase activity at high doses $(100 \mu \mathrm{M})$ and a low dose (1 to $10 \mu \mathrm{M}$ ) potentiation of the ability of other agonists (such as NE) to stimulate cAMP production in a variety of systems (Seamon et al., 1981). The concentration of forskolin used in our experiments is probably too low to directly stimulate adenylate cyclase activity, but it is sufficient to prime the cyclase for enhanced stimulation by the residual NE present in the depleted slices and thus, to restore the ability of these slices to exhibit LTP.

Perhaps the most interesting feature of these results is the area
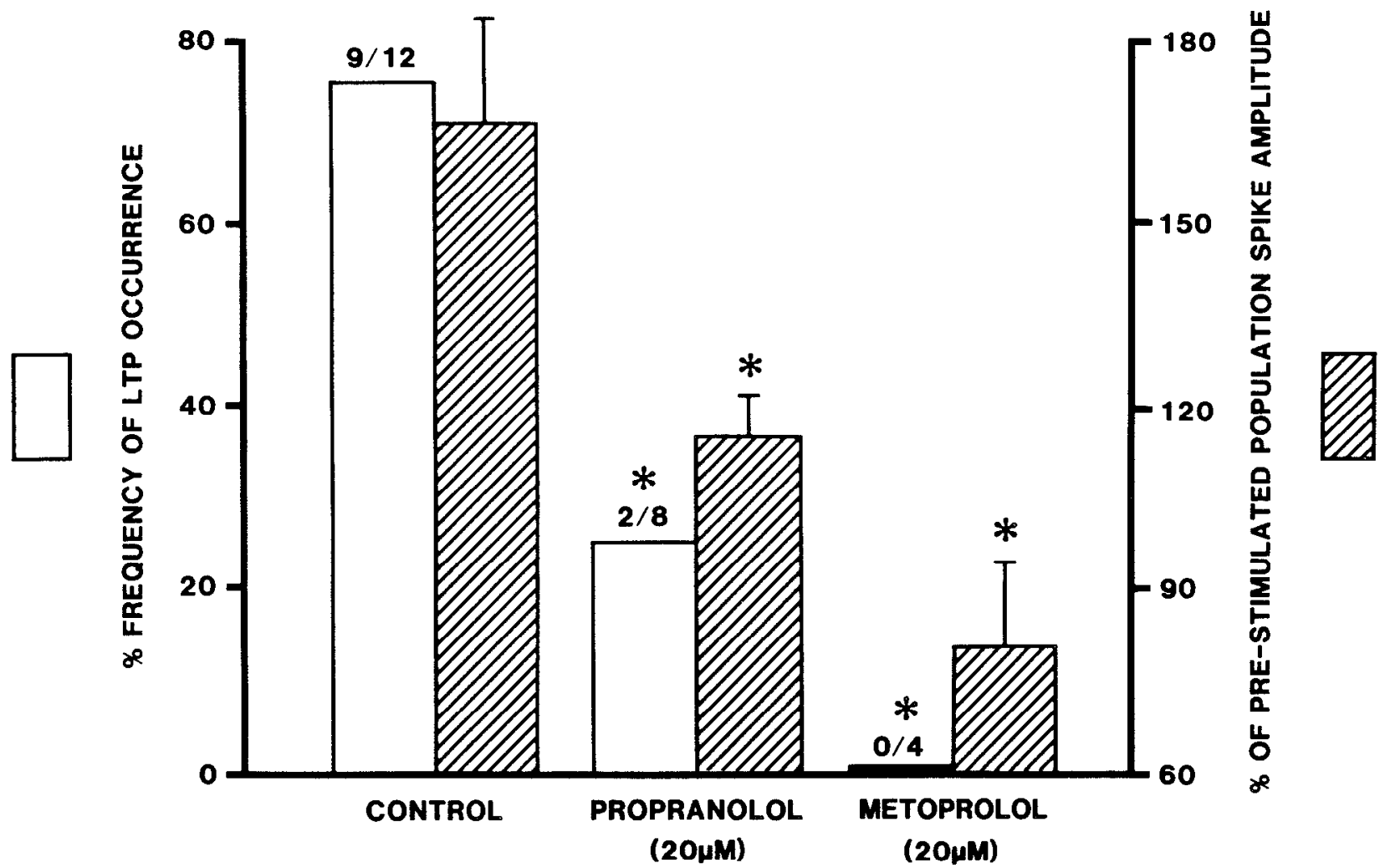

Figure 5. Percentage of occurrence of LTP (open bars) and percentage of increase in population spike amplitude (mean \pm SEM, hatched bars) in the

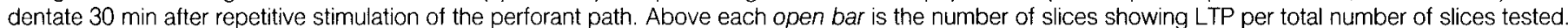

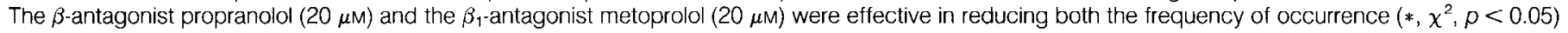
and the amplitude increase $(*$, Student's $t$ test, $\rho<0.05)$, of LTP in the dentate. 

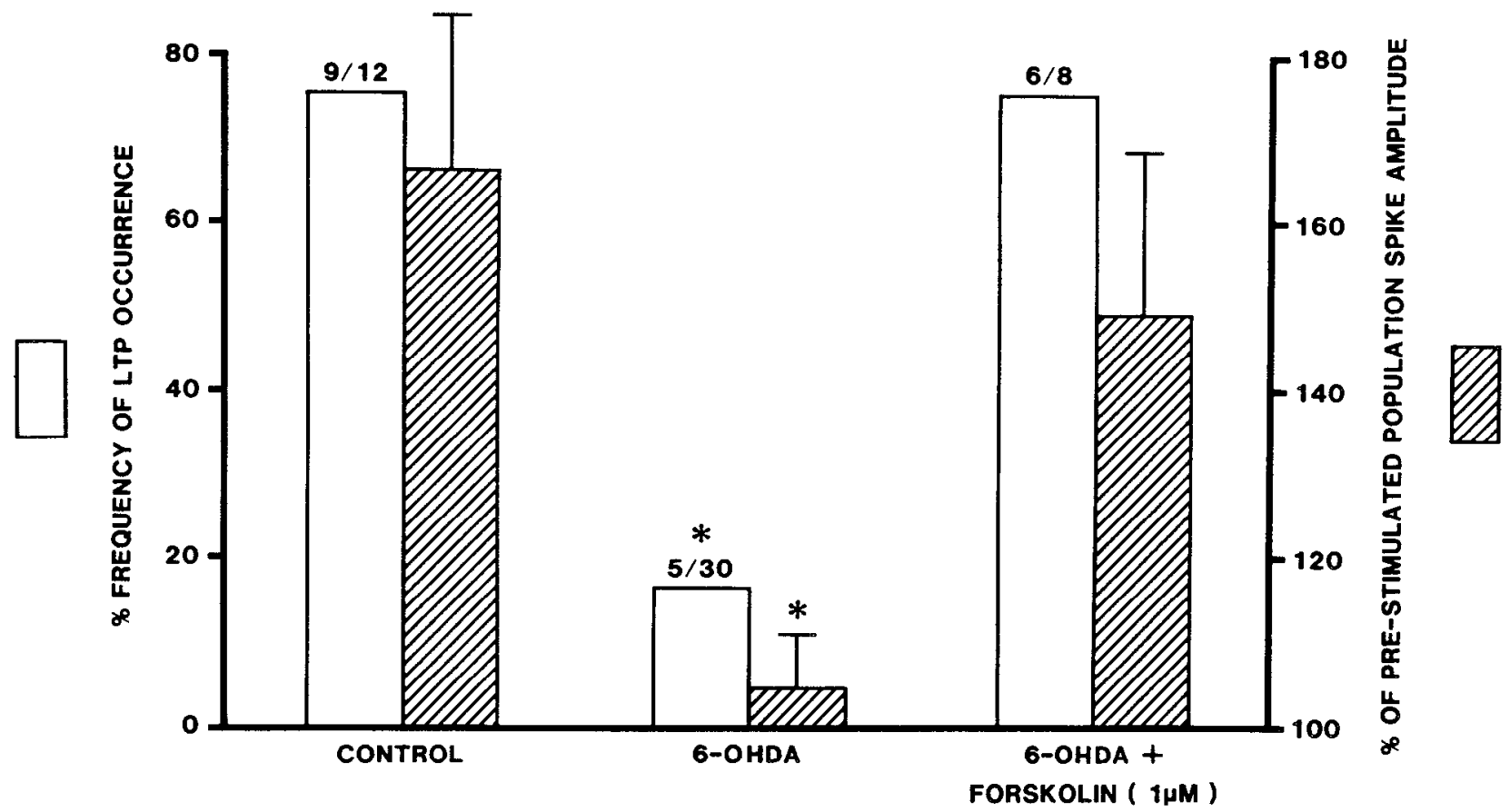

Figure 6. Percentage of occurrence of LTP (open bars) and percentage of increase in population spike amplitude (mean \pm SEM, hatched bars) in the dentate $30 \mathrm{~min}$ after repetitive stimulation of the perforant path. Above each open bar is the number of slices showing LTP per total number of slices tested As previously shown, depletion of NE with 6-OHDA markedly reduces both the frequency of occurrence $\left(*, \chi^{2}, p<0.05\right)$ and the increased population spike amplitude (*, Student's $t$ test, $p<0.05)$ of LTP in the dentate. However, when NE-depleted slices were preincubated for 30 min with the adenylate cyclase stimulant forskolin $(1 \mu \mathrm{M})$ prior to repetitive stimulation, LTP was restored to control values. This concentration of forskolin had no effect alone on the population spike amplitude (not shown)

specificity they exhibit. Experiments examining the long-term effects of NE stimulation of adenylate cyclase on biochemical parameters and membrane properties may be more likely to yield changes in the dentate than in field CA1. In facl, our laboralory and others have shown that NE produces a long-lasting potentiation in the dentate (Lacaille and Harley, 1983; Neuman and Harley, 1983; Stanton and Sarvey, 1984b). In contrast, very recent work has suggested that there is a long-lasting potentiation produced by dopamine in field CA1 which may be mediated by intracellular rises in CAMP (Gribkoff and Ashe, 1984; Gribkoff et al., 1984; Lin-Liu et al., 1984; Mody and Miller, 1984), whereas dopamine does not produce potentiation in the dentate (P. K. Stanton and J. M. Sarvey, unpublished results). NE and dopamine may prove to be area-specific potentiators with final common mechanisms of action.

Previously, we have shown that inhibitors of protein synthesis are capable of blocking LTP in field CA1 (Stanton and Sarvey, 1984c) and that protein synthesis inhibitors also block the long-lasting potentiation produced in the dentate by direct application of NE (Stanton and Sarvey, 1984b). Furthermore, protein synthesis inhibitors are effective in blocking LTP in the dentate (P. K. Stanton and J. M. Sarvey, unpublished results). Taken together, these results indicate that future experiments are needed to examine the effects of NE and of elevated intracellular cAMP levels produced by many transmitters on newly synthesized proteins in the dentate. The wealth of competing mechanisms in the neuronal plasticity literature has hinted at the possibility of multiple stimulating and inhibiting pathways for neuronal plasticity, perhaps with some final common mechanisms (Swanson et al., 1982). Our results suggest that convergence of some of these mechanisms in pharmacologically distinct, but electrophysiologically interacting, cell areas may predispose the hippocampus to long-term plastic changes.

The results presented here suggest separate sites of action for NE and 5-HT in the production of LTP first elucidated in vivo by Bliss et al. (1983). Our results support the hypothesis that NE endogenous to the hippocampus is important to the expression of LTP, whereas the sites of action of 5-HT are probably remote to this structure. Furthermore, we have identified the probable involvement of $\beta_{1}$. receptor activation of adenylate cyclase in NE's actions. An interesting question remaining to be answered concerns what temporal contingency is required between noradrenergic activity and the conditioning train. Co-stimulation experiments with electrodes placed in the locus ceruleus or the median raphe nucleus and in the angular bundle should answer this question. Hippocampal monoaminergic systems should provide a useful tool for the study of potentiative mechanisms and their relation to long-term neuronal plasticity.

\section{References}

Alger, B. E., and T. J. Teyler (1976) Long-term and short-term plasticity in the $\mathrm{CA} 1, \mathrm{CA} 3$, and dentate regions of the hippocampal slice. Brain Res. 110: 463-480.

Andersen, P., T. V. P. Bliss, and K. K. Skrede (1971) Unit analysis of hippocampal population spikes. Exp. Brain Res. 13: 222-238.

Andersen, P., S. H. Sundberg, O. Sveen, and H. Wingström (1977) Specific long-lasting potentiation of synaptic transmission in hippocampal slices. Nature 266: 736-737

Assat, S. Y., S. T. Mason, and J. J. Miller (1979) Noradrenergic modulation of neuronal transmission between the entorhinal cortex and the dentate gyrus of the rat. J. Physiol. (Lond.) 292: 52P.

Azmitia, E. C., and M. Segal (1978) ^n autoradiographic analysis of the differential ascending projections of the dorsal and median raphe nuclei in the rat. J. Comp. Neurol. 179: 641-668.

Berger, T. W. (1984) Long-term potentiation of hippocampal synaptic transmission affects rate of behavioral learning. Science 224: 627-630

Bliss, T. V. P., and A. R. Gardner-Medwin (1973) Long-lasting potentiation of synaptic transmission in the dentate area of the unanaesthetized rabbit following stimulation of the perforant path. J. Physiol. (Lond.) 232: 357 374.

Bliss, T. V. P., and T. Lømo (1973) Long-lasting potentiation of synaptic transmission in the dentate area of the anaesthetized rabbit following stimulation of the perforant path. J. Physiol. (Lond.) 232: 331-356.

Bliss, T. V. P., and S. Wendlandt (1977) Effects of stimulation of locus 
coeruleus on synaptic transmission in the hippocampus. Proc. Int. Union Physiol. Sci. 13: 81 .

Bliss, T. V. P., G. V. Goddard, and M. Riives (1983) Reduction of long-term potentiation in the dentate gyrus of the rat following selective depletion of monoamines. J. Physiol. (Lond.) 331: 175-191.

Bradford, M. M. (1976) A rapid and sensitive method for the quantitation of microgram quantities of protein utilizing the principle of protein-dye binding. Anal. Biocherm. 72: 248-254.

Conrad, L. C. A., C. M. Leonard, and D. W. Pfaff (1974) Connections of the median and dorsal raphe nuclei in the rat. An autoradiographic and degenerative study. J. Comp. Neurol. 156: 179-205.

Crow, T. J., and S. Wendlandt (1976) impaired acquisition of a passive avoidance response after lesions induced in the locus coeruleus by $6-\mathrm{OH}$. dopamine. Nature 259: 42-44.

Crutcher, K. A., and J. N. Davis (1980) Hippocampal alpha- and betaadrenergic receptors: Comparisons of $\left[{ }^{3} \mathrm{H}\right]$ dihydroalprenol and $\left[{ }^{3} \mathrm{H}\right] \mathrm{WB}$ 4101 binding with noradrenergic innervation in the rat. Brain Res. 182. 107-117.

Dahi, D., W. H. Bailey, and J. Wirson (1983) Effect of norepinephrine depletion of hippocampus on neuronal transmission from perforant path. way through dentate gyrus. J. Neurophysiol. 49: 123-133.

Douglas, R. M., and G. V. Goddard (1975) Long.term potentiation of the perforant path-granule cell synapse in the rat hippocampus. Brain Res. 86: 205-215.

Douglas, R. M., G. V. Goddard, and M. Rilves (1982) Inhibitory modulation of LTP: Evidence for a postsynaptic locus of control. Brain Res. 240: 259272.

Goldstein. A. (1964) Biostatistics: An Introductory Text. pp. 129-146, MacMillan Publishing Co., New York.

Gribkoff, V. K., and J. H. Ashe (1984) Modulation by dopamine of population responses and cell membrane properties of hippocampal CA1 neurons in vitro. Brain Res. 292: 327-338.

Gribkoff, V. K., J. H. Ashe, W. H. Fletcher, and M. E. Lekama (1984) Dopamine, cyclic AMP, and protein kinase produce a similar long-lasting increase in input resistance in hippocampal CA1 neurons. Soc. Neurosci. Abstr. 10: 898.

Haas, H. L. (1984) Brain Slices, R. Dingledine, ed., pp. 145-147, Plenum Press, New York.

Haas, H. L., and A. Konnerth (1983) Histamine and noradrenaline decrease calcium-activated potassium conductance in hippocampal pyramidal cells. Nature 302: 432-434

Huang. R., M. F. Smith, and W. L. Zahler (1982) Inhibition of forskolinactivated adenylate cyclase by ethanol and other solvents. J. Cyclic Nucleotide Res. 8: 385-394.

König. J. F. R., and R. A. Klippel (1963) The Rat Brain: A Stereotactic Atlas, Robert E. Krieger Publishing Co., Huntington, NY.

Lacaille, J. C., and C. W. Harley (1983) In vitro superfusion of norepinephrine potentiates the perforant path evoked field potential in the dentate gyrus. Soc. Neurosci. Abstr. 9: 1001.

Langmöen, I. A., M. Segal, and P. Anderson (1981) Mechanisms of norepinephrine actions on hippocampal pyramidal cells in vitro. Brain Res. 208 : 349-362.

Lindvall, O., and A. Björklund (1974) The organization of ascending catecholamine neuron systems in the rat brain as revealed by the glyoxylic acid fluorescence technique. Acta Physiol. Scand. Suppl. 412: 1-48.

Lin-Liu. S., C. Cain, J. M. Bawin, and W. R. Adey (1984) Effects of forskolin on cAMP level and excitability in hippocampal slices. Soc. Neurosci. Abstr. 10: 898 .

Loy, R., D. A. Koziell, J. D. Lindsey, and R. Y. Moore (1980) Noradrenergic innervation of the adult rat hippocampal formation. J. Comp. Neurol. 189: $699-710$.

Madison, D. V., and R. A. Nicoll (1982) Noradrenaline blocks accommodation of pyramidal cell discharge in the hippocampus. Nature 299: 636-638.

Maickel, R. P., R. H. Cox, J. Saillant, and F. P. Miher (1968) A method for the determination of serotonin and norepinephrine in discrete areas of rat brain. Int. J. Neuropharmacol. 7:275-281.

Manier, D. H., D. D. Gillespie, and F. Sulser (1984) Role of $5 \mathrm{HT}$ in the regulation of beta adrenoceptors (BAC) by desipramine (DMI). Pharmacologist 26: 215 .

Mason, S. T., and S. D. Iversen (1977) Effects of selective noradrenaline loss on behavioral inhibition in the rat. J. Comp. Physiol. Psychol. 91: 165-173.

Milner, B. (1972) Disorders of learning and memory after temporal lobe lesions in man. Clin. Neurosurg. 19: 421-446.

Mody, I., and J. J. Miller (1984) Long-term potentiation (LTP) induced by IBMX in the CA1 region of rat hippocampus. Soc Neurosci. Abstr. 10: 418.

Mueller, A. L., B. J. Hoffer, and T. V. Dunwiddie (1981) Noradrenergic responses in rat hippocampus: Evidence for mediation by $\alpha$ and $\beta$ receptors in the in vitro slice. Brain Res. 214: 113-126.

Neuman, R. S., and C. W. Harley (1983) Long-lasting potentiation of the dentate gyrus population spike by nurepinephrine. Brain Res. 273: 162165.

Noble, E. P., R. J. Wurtman, and J. Axelrod (1967) A simple and rapid method for injecting $\mathrm{H}^{3}$-norepnephrine into the lateral ventricle of the rat brain. Brain 6: 281-291.

Schwartzkroin, P. A., and K. Wester (1975) Long-lasting facilitation of a synaptic potential following tetanization in the in vitro hippocampal slice. Brain Res. 89: 107-119.

Seamon, K. B., W. Padgett, and J. W. Daly (1981) Forskolin: Unique diterpene activation of adenylate cyclase in membranes and in intact cells. Proc. Natl. Acad. Sci. (U.S.A.) 78: 3363.

Segal, M. (1982) Norepinephrine modulates reactivity of hippocampal cells to chemical stimulation in vitro. Exp. Neurol. 77: 86-93.

Segal, M., and F. E. Bloom (1974) The action of norepinephrine in the rat hippocampus. II. Activation of the input pathway. Brain Res. 77: 99-114.

Stanton, P. K., and J. M. Sarvey (1984a) Depletion of norepinephrine (NE), but not serotonin (5-HT), specifically reduces long-term potentiation (LTP) in dentate of rat hippocampal slices. Pharmacologist 26: 135.

Stanton, P. K., and J. M. Sarvey (1984b) Inhibition of protein synthesis specifically blocks norepinephrine-induced long-lasting potentiation in the fascia dentata of rat hippocampal slices. Soc. Neurosci. Abstr. 10: 76 .

Stanton, P. K., and J. M. Sarvey (1984c) Blockade of long-term potentiation in rat hippocampal CA1 region by inhibitors of protein synthesis. $J$. Neurosci. 4: 3080-3088.

Stevens, D. A., L. D. Fechter, and O. Resnick (1969) The effects of $\rho$ chlorophenylalanine, a depletor of brain serotonin, on behavior. II. Retardation of passive avoidance learning. Life Sci. 8 (Part II): 379.

Swanson, L. W. T. J. Teyler, and R. F. Thompson (1982) Hippocampal longterm potentiation: Mechanisms and implications for memory. Neurosci. Res. Program Bull. 20: 613-769.

Ungerstedt, U. (1971) Stereotaxic mapping of the monoamine pathways in the rat brain. Acta. Physiol. Scand. Suppl. 367: 1-48.

Winson, J. (1980) Influence of raphé nuclei on neuronal transmission from perforant pathway through dentate gyrus. J. Neurophysiol. 44: 937-950. 